\title{
UNIFORMLY $\gamma$-RADONIFYING FAMILIES OF OPERATORS AND THE STOCHASTIC WEISS CONJECTURE
}

\author{
BERNHARD H. HAAK AND JAN VAN NEERVEN
}

Abstract. We introduce the notion of uniform $\gamma$-radonification of a family of operators, which unifies the notions of $R$-boundedness of a family of operators and $\gamma$-radonification of an individual operator. We study the properties of uniformly $\gamma$-radonifying families of operators in detail and apply our results to the stochastic abstract Cauchy problem

$$
d U(t)=A U(t) d t+B d W(t), \quad U(0)=0 .
$$

Here, $A$ is the generator of a strongly continuous semigroup of operators on a Banach space $E, B$ is a bounded linear operator from a separable Hilbert space $H$ into $E$, and $W_{H}$ is an $H-$ cylindrical Brownian motion. When $A$ and $B$ are simultaneously diagonalisable, we prove that an invariant measure exists if and only if the family

$$
\left\{\sqrt{\lambda} R(\lambda, A) B: \lambda \in S_{\vartheta}\right\}
$$

is uniformly $\gamma$-radonifying for some/all $0<\vartheta<\frac{\pi}{2}$, where $S_{\vartheta}$ is the open sector of angle $\vartheta$ in the complex plane. This result can be viewed as a partial solution of a stochastic version of the Weiss conjecture in linear systems theory.

Mathematics subject classification (2010): Primary: 47B10, Secondary: 35R15, 47D06, 60H15, 93B28. Keywords and phrases: Uniformly $\gamma$-radonifying families of operators, $R$-boundedness, Laplace transforms, stochastic evolution equations, invariant measures, stochastic Weiss conjecture.

\section{REFERENCES}

[1] W. ARENDT AND S. BU, The operator-valued Marcinkiewicz, multiplier theorem and maximal regularity, Math. Z. 240 (2002), no. 2, 311-343.

[2] E. BerKSON AND T. A. GILlespie, Spectral decompositions and harmonic analysis on UMD spaces, Studia Math. 112 (1994), no. 1, 13-49.

[3] V. I. Bogachev, Gaussian Measures, Mathematical Surveys and Monographs, vol. 62, American Mathematical Society, Providence, RI, 1998.

[4] J. Bourgain, Vector-valued singular integrals and the $H^{1}-B M O$ duality, Probability Theory and Harmonic Analysis (Cleveland, Ohio, 1983), Monogr. Textbooks Pure Appl. Math., vol. 98, Dekker, New York, 1986, pp. 1-19.

[5] P. Clément, B. De Pagter, F. A. Sukochev, and H. Witvliet, Schauder decompositions and multiplier theorems, Studia Math. 138 (2000), no. 2, 135-163.

[6] M. Cowling, I. Doust, A. McIntosh, AND A. YAGi, Banach space operators with a bounded $H^{\infty}$ functional calculus, J. Austral. Math. Soc. Ser. A 60 (1996), no. 1, 51-89.

[7] R. DENK, M. HIEBER, AND J. PRÜSS, R-boundedness, Fourier multipliers and problems of elliptic and parabolic type, Mem. Amer. Math. Soc. 166 (2003), no. 788.

[8] J. Dettweiler, J. M. A. M. Van Neerven, And L. Weis, Space-time regularity of solutions of the parabolic stochastic Cauchy problem, Stoch. Anal. Appl. 24 (2006), no. 2, 843-869.

[9] S. Diaz AND F. Mayoral, On compactness in spaces of Bochner integrable functions, Acta Math. Hungar. 83 (1999), no. 3, 231-239.

[10] J. Diestel, H. Jarchow, And A. Tonge, Absolutely Summing Operators, Cambridge Studies in Advanced Mathematics, vol. 43, Cambridge University Press, Cambridge, 1995. 
[11] J. Diestel, W. M. Ruess, And W. Schachermayer, On weak compactness in $L^{1}(\mu, X)$, Proc. Amer. Math. Soc. 118 (1993), no. 2, 447-453.

[12] M. GiRARDi And L. WeIs, Operator-valued Fourier multiplier theorems on Besov spaces, Math. Nachr. 251 (2003), 34-51.

[13] B. H. HAAK, Kontrolltheorie in Banachräumen und quadratische Abschätzungen, Ph.D. thesis, Karlsruhe, 2004.

[14] B. H. HAAK AND P. C. KUnstmann, Admissibility of unbounded operators and wellposedness of linear systems in Banach spaces, Integral Eq. Operator Th. 55 (2006), 497-533.

[15] B. H. HaAK, J. M. A. M. VAn NeERVEn, AND M. C. Veraar, A stochastic Datko-Pazy theorem, J. Math. Anal. Appl. 329 (2007), no. 2, 1230-1239.

[16] J. Hoffmann-JøRGEnsen, Sums of independent Banach space valued random variables, Studia Math. 52 (1974), 159-186.

[17] T. P. HytÖNEn, Littlewood-Paley-Stein theory for semigroups in UMD spaces, Rev. Mat. Iberoam. 23 (2007), no. 3, 973-1009.

[18] T. P. Hytönen And L. Weis, An operator-valued $T_{b}$ theorem, J. Functional Anal. 234 (2006), 420-463.

[19] B. JACOB AND J. R. PARTINGTON, The Weiss conjecture on admissibility of observation operators for contraction semigroups, Integral Eq. Operator Th. 40 (2001), no. 2, 231-243.

[20] B. JACOB AND H. ZWART, Exact observability of diagonal systems with a one-dimensional output operator, Int. J. Appl. Math. Comput. Sci. 11 (2001), no. 6, 1277-1283.

[21] M. Junge, C. Le Merdy, AND Q. Xu, Calcul fonctionnel et fonctions carrées dans les espaces Lp non commutatifs, C. R. Math. Acad. Sci. Paris 337 (2003), no. 2, 93-98.

[22] C. KAISER AND L. WeIS, Wavelet transform for functions with values in UMD spaces, Studia Math. 186 (2008), no. 2, 101-126.

[23] N. J. Kalton, P. C. Kunstmann, And L. Weis, Perturbation and interpolation theorems for the $H^{\infty}$-calculus with applications to differential operators, Math. Ann. 336 (2006), 747-801.

[24] N. J. KALtON AND L. WeIs, Euclidian structures, In preparation.

[25] N. J. KALtON AND L. WeIs, The $H^{\infty}$-calculus and square function estimates, In preparation.

[26] P. C. Kunstmann AND L. Weis, Maximal $L_{p}$-regularity for parabolic equations, Fourier multiplier theorems and $H^{\infty}$-functional calculus, Functional Analytic Methods for Evolution Equations, Lecture Notes in Math., vol. 1855, Springer, Berlin, 2004, pp. 65-311.

[27] S. KWAPIEŃ, On Banach spaces containing $c_{0}$, Studia Math. 52 (1974), 187-188, A supplement to the paper by J. Hoffmann-Jørgensen: "Sums of independent Banach space valued random variables" (Studia Math. 52 (1974), 159-186).

[28] C. LE MERdy, The Weiss conjecture for bounded analytic semigroups, J. London Math. Soc. (2) 67 (2003), no. 3, 715-738.

[29] C. Le Merdy, On square functions associated to sectorial operators, Bull. Soc. Math. France 132 (2004), no. 1, 137-156.

[30] V. Linde And A. Pietsch, Mappings of Gaussian measures of cylindrical sets in Banach spaces, Teor. Verojatnost. i Primenen. 19 (1974), 472-487, English translation in: Theory Probab. Appl. 19 (1974), 445-460.

[31] A. McIntosh, Operators which have an $H^{\infty}$ functional calculus, Miniconference on operator theory and partial differential equations (North Ryde, 1986), Proc. Centre Math. Anal. Austral. Nat. Univ., vol. 14, Austral. Nat. Univ., Canberra, 1986, pp. 210-231.

[32] J. M. A. M. van NeErven, Compactness in vector-valued Banach function spaces, Positivity 11 (2007), no. 3, 461-467.

[33] J. M. A. M. VAN NEERVEN, $\gamma$-radonifying operators - a survey, The AMSI-ANU Workshop on Spectral Theory and Harmonic Analysis, Proc. Centre Math. Appl. Austral. Nat. Univ., vol. 44, Austral. Nat. Univ., Canberra, 2010, pp. 1-61.

[34] J. M. A. M. van Neerven, M. C. Veraar, And L. Weis, Stochastic integration in UMD Banach spaces, Ann. Probab. 35 (2007), no. 4, 1438-1478.

[35] J. M. A. M. van Neerven, M. C. VeraAr, And L. Weis, Stochastic evolution equations in UMD Banach spaces, J. Funct. Anal. 255 (2008), no. 4, 940-993.

[36] J. M. A. M. VAn NEERVEN AND L. WeIS, Stochastic integration of functions with values in a Banach space, Studia Math. 166 (2005), no. 2, 131-170. 
[37] J. M. A. M. VAN NEERVEN AND L. WEIS, Weak limits and integrals of Gaussian covariances in Banach spaces, Probab. Math. Statist. 25 (2005), no. 1, 55-74.

[38] J. M. A. M. VAN NEERVEN AND L. WEIS, Invariant measures for the linear stochastic Cauchy problem and $R$-boundedness of the resolvent, J. Evolution Equ. 6 (2006), no. 2, 205-228.

[39] A.L. NEIDHARDT, Stochastic integrals in 2-uniformly smooth Banach spaces, Ph. D. thesis, University of Wisconsin, 1978.

[40] B. De Pagter, H. Witvliet, And F. A. Sukochev, Double operator integrals, J. Funct. Anal. 192 (2002), no. 1, 52-111.

[41] G. PISIER, The Volume of Convex Bodies and Banach Space Geometry, Cambridge Tracts in Mathematics, vol. 94, Cambridge University Press, Cambridge, 1989.

[42] B. Russo And H. A. Dye, A note on unitary operators in $C^{*}$-algebras, Duke Math. J. 33 (1966), 413-416.

[43] N. TomczaK-Jaegermann, Banach-Mazur Distances and Finite-Dimensional Operator Ideals, Pitman Monographs and Surveys in Pure and Applied Mathematics, vol. 38, Longman Scientific \& Technical, Harlow, 1989.

[44] M. C. VeraAR AND J. Zimmerschied, Non-autonomous stochastic Cauchy problems in Banach spaces, Studia Math. 185 (2008), no. 1, 1-34.

[45] L. WEIS, Operator-valued Fourier multiplier theorems and maximal Lp-regularity, Math. Ann. 319 (2001), no. 4, 735-758.

[46] G. WEISS, Admissibility of unbounded control operators, SIAM J. Control Optim. 27 (1989), no. 3, $527-545$

[47] G. WEISs, Two conjectures on the admissibility of control operators, "Estimation and Control of Distributed Parameter Systems" (Vorau, 1990), Internat. Ser. Numer. Math., vol. 100, Birkhäuser, Basel, 1991, pp. 367-378.

[48] GEORGE WEISS, Admissibility of input elements for diagonal semigroups on 12 , Systems Control Lett. 10 (1988), no. 1, 79-82.

[49] GeORGE WeIss, Admissible observation operators for linear semigroups, Israel J. Math. 65 (1989), no. $1,17-43$.

[50] D. V. Widder, Functions harmonic in a strip, Proc. Amer. Math. Soc. 12 (1961), 67-72.

[51] R. M. Young, An Introduction to Nonharmonic Fourier Series, first ed., Academic Press Inc., San Diego, CA, 2001. 